\title{
Quantitative Relationship of the Nutritional Quality of Spinach with Temperature and Duration in Root Area Chilling Treatment
}

\author{
Ayana Ito ${ }^{1}$, Hiroshi Shimizu², Ryosuke Hiroki ${ }^{2}$, Hiroshi NAKASHIMA², Juro MiYASAKA ${ }^{2}$ and Katsuaki OHDOI ${ }^{2}$ \\ 'Daiwa House Industry, Central Research Laboratory, 6-6-2 Sakyo, Nara 631-0801, Japan \\ ${ }^{2}$ Graduate School of Agriculture, Kyoto University, Kyoto 606-8502, Japan
}

(Received April 8, 2014; Accepted January 7, 2015)

\begin{abstract}
Several studies have reported that the nutritional quality of spinach is enhanced by application of cold stress to the root area. However, the relationship of the nutritional value of spinach with the root area temperature and duration of root area chilling has not been investigated. Here, we examine the ascorbic acid, nitrate ion, and soluble solid content of spinach subjected to root area chilling in a nutrient solution for $2,4,5,6$, and 7 days at various temperatures $\left(4,6,10\right.$, and $\left.14^{\circ} \mathrm{C}\right)$. Under all temperature conditions, the nitrate ion concentration significantly decreased within 2 days of the onset of chilling. Ascorbic acid and soluble solid content showed similar trends; significant change in concentrations of both the compounds occurred after 4 days at $4^{\circ} \mathrm{C}, 5$ days at $6^{\circ} \mathrm{C}, 6$ days at $10^{\circ} \mathrm{C}$, and 7 days at $14^{\circ} \mathrm{C}$. On the basis of these results, we developed the relational expression for the chilling duration and solution temperature. The results of this study indicate that adjusting the chilling duration and solution temperature according to the relational expression would help plant factories produce high value-added spinach.
\end{abstract}

Keywords : ascorbic acid, environment control, nitrate ion, plant factory, soluble solid content

\section{INTRODUCTION}

Plant factories are clean farming facilities that produce high quality vegetables year-round; pesticide use is not required in these facilities because the growth environment of plants is isolated from the outside environment. These facilities have been recognized as a solution to food insecurity due to growth in world population, and bad harvests caused by abnormal climatic variations. Recently, studies on the production of high value-added vegetables in plant factories, using environmental controls or certain stimuli have attracted much attention (Kitano et al., 2008; Akita and Suzuki, 2010). Spinach is a green leaf-vegetable with health benefits because of its rich nutritional content. However, the nutrient quality of spinach varies over the year (Tamura, 2004; Fujiwara et al., 2005). Therefore, much research has been focused on cultivating high-quality spinach in plant factories year-round. Previous research has shown that cold stress to the root area of spinach has a positive effect on the nutritional quality, and produces a significant increase in beneficial substances (such as sugars, ascorbic acid, and $\mathrm{Fe}^{2+}$ ) and a decrease in harmful substances (such as $\mathrm{NO}_{3}{ }^{-}$and oxalic acid) (Chadirin et al., 2011a; 2011b; 2012). Furthermore, a recent study has indicated that 6 days is the optimal duration for root area chilling to produce high quality spinach, when the temperature of the nutrient solution is controlled at $10^{\circ} \mathrm{C}$ under plant factory conditions (Ito et al., 2013).

Although root area chilling is known to enhance the nutritional quality of spinach, information remains limited about the relationship between chilling temperature, the duration of cold treatment, and the nutritional quality of spinach. By regulating the temperature of the culture solution below $10^{\circ} \mathrm{C}$, a greater amount of valuable constituents may accumulate over a shorter duration (i.e., less than 6 days). This study aimed to reveal the triadic relationship between nutrient solution temperature during chilling treatment, chilling duration, and the nutritional components of spinach. Specifically, changes in the content of ascorbic acid, sugar, and nitrate ions were calculated to evaluate the nutritional quality of spinach cultivated under different temperature conditions and timeframes. The results were used to quantify the minimum degree of cold stress required to enhance the nutritional value of spinach. This information is anticipated to contribute towards establishing cultivation technology that produces high-quality vegetables with lower power consumption under plant factory conditions.

\section{MATERIALS AND METHODS}

Plant materials and conditions

Spinach (Spinacia oleracea L. 'Active') seeds were sown on a water-soaked sponge made of flexible polyurethane foam. After one week, the germinated seedlings were transplanted to a hydroponic system in a growth chamber (KCLP-1000, Nippon Medical \& Chemical Instruments Co., Ltd., chamber 1, Osaka, Japan). The cultivation conditions were set at a photoperiod of $14 \mathrm{~h}$ (06:00 $\mathrm{h}$ to 20:00 h), a photosynthetic photon flux density (PPFD) of $200 \mu \mathrm{mol} \mathrm{m} \mathrm{m}^{-2} \mathrm{~s}^{-1}$ provided by LED lights (NE02000089 (01); Shibasaki, Saitama, Japan) installed at 325

Corresponding author: Hiroshi Shimizu, fax: +81-75-753-6165, e-mail : hshimizu@kais.kyoto-u.ac.jp 
$\mathrm{mm}$ above the cultivation panel, a day/night air temperature regime of $23 / 18^{\circ} \mathrm{C}$. The temperature of the nutrient solution was set at $18^{\circ} \mathrm{C}$ and was adjusted to an electric conductivity (EC) of 1.2 using Otsuka-A prescription (OAT Agrio Co., Ltd., Tokyo, Japan). Ten plants under each experimental condition were used. The temperature of the nutrient solution was controlled by a water temperature controller (ZC-700; Zensui, Japan), and the nutrient solution pumped from the tank was continuously circulated. The temperature of the rhizosphere of each cultivation panel was monitored by a thermocoupled sensor and data logger (CR-10X; Campbell Scientific, Logan, Utah, USA).

Spinach plants were grown under 24 different experimental conditions. First, all plants were grown under control conditions in chamber 1 (Fig. 1A). On the 21st day (as shown in Fig. 1B), ten plants were transferred to a hydroponic system in a second growth chamber (chamber 2 ), in which the nutrient solution temperature was regulated at $4,6,10$, and $14^{\circ} \mathrm{C}$. On the following day, a further 10 plants were transferred to the hydroponic system in the second growth chamber (Fig. 1C), with another 10 plants being transferred 2, 3, and 5 days later. Thus, spinach plant roots were exposed to different low temperature conditions for the respective durations of 2, 4, 5, 6 and 7 days. In this procedure, the root area of spinach plants was subjected to cold stress for different durations. The experiment was repeated for all four temperature conditions $(4,6,10$, and 14 $\left.{ }^{\circ} \mathrm{C}\right)$. For all 24 experimental conditions, spinach plants were grown using the hydroponic "nutrient film technique" (NFT). When using the NFT, large parts of the root are exposed to the air, except for the root part that is submerged in the culture solution. The experiments of different chilling durations were conducted in succession at a constant temperature of the nutrient solution in chamber 2 to achieve the all experiment combinations mentioned above. The experiment was conducted over a 28-day period, after which

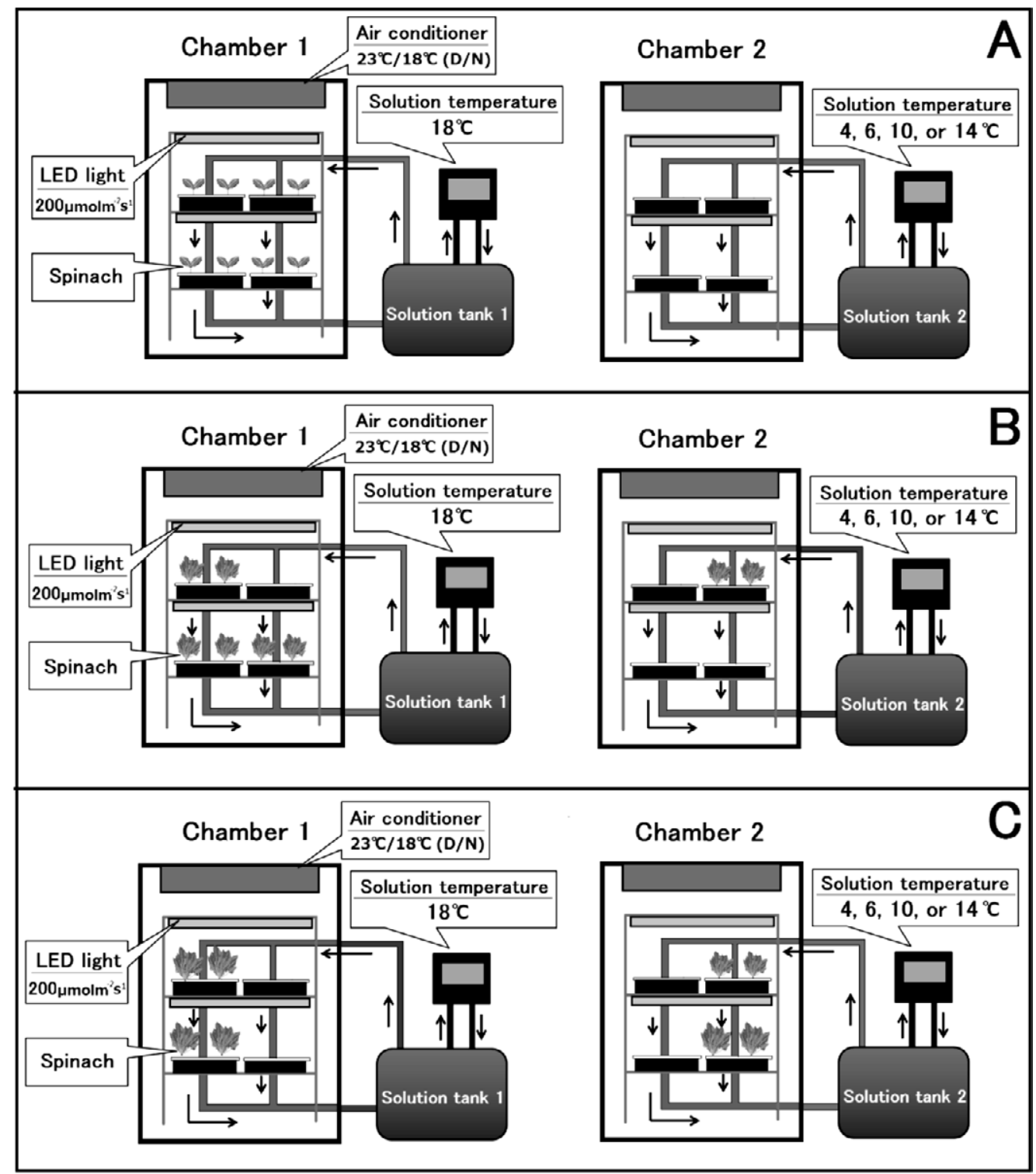

Fig. 1 Schematic diagram of the spinach cultivation experiment. Spinach plants were grown under controlled conditions in chamber 1 for 20 days (A). On the 21 st day, 10 plants were transferred to chamber 2, where the temperature of the nutrient solution was regulated at $4,6,10$, and $14^{\circ} \mathrm{C}(\mathrm{B})$. A further 10 plants were transferred the following day (C), and then after a further 2,3 , and 5 days. 
all spinach plants were harvested simultaneously. Five plants from each experimental condition were analyzed for the different components, while another five plants were used to measure the fresh weight, dry weight, and area of the largest leaf.

Determination of ascorbic acid and nitrate ion content

Ascorbic acid content and nitrate ion concentrations were measured using a reflection photometer (RQflex 10; Merck, Tokyo, Japan). The spinach was placed in a blender with 5\% metaphosphoric acid, and was blended to form a liquid. The liquid was further diluted by adding $5 \%$ metaphosphoric acid. The solid components were then removed by centrifugation (Centrifuge 5415R; Eppendorf, Tokyo, Japan). Tsukazawa (2002) reported that both high performance liquid chromatography (HPLC) and RQflex produce very similar ascorbic acid content; hence, correction was unnecessary. Nitrate ion content was measured in a similar manner to that of ascorbic acid, except that the spinach was blended using reverse osmosis water. Subsequent analytic procedures were the same as those used for ascorbic acid. HPLC and RQflex measurements of nitrate ion content in spinach were previously shown to be highly correlated (Takebe and Yoneyama, 1995).

Determination of soluble solid content

The measurement of total soluble solids in vegetables gives a fairly good indication of the sugar content. Soluble solid content was measured using a Brix meter (POTSDTM1; Thanko, Tokyo, Japan), following the method reported by Shishido (2008). Petioles were collected from the leaf with the maximal length and the facing leaf. Both stems were mashed using a muddler. A drop of the filtrate was then placed onto the Brix meter to measure the soluble solid content.

Sampling and analysis

The data presented for the growth parameters are the means of five replicates \pm standard deviation (SD). Ryan's multiple comparison test was performed with statistical significance accepted at $P<0.05$.

\section{RESULTS AND DISCUSSION}

The physical appearance of the spinach plants subjected to each of the 24 experimental conditions is shown in Fig. 2. At the same solution temperature, plants tended to be increasingly shorter and flatter with increasing duration of root chilling. For the same duration of chilling treatment, the size of spinach plants increased with increasing solution temperature. However, none of the plants exhibited any physiological disorders.

The effect of different levels of cold stress to the root area on the fresh weight of the aerial part, the dry matter percentage, and the leaf area of the largest leaf are shown in Tables 1, 2, and 3, respectively. Under the same solution temperature conditions, the fresh weight and leaf area decreased with increasing chilling duration. For the same duration of root chilling, the fresh weight and leaf area

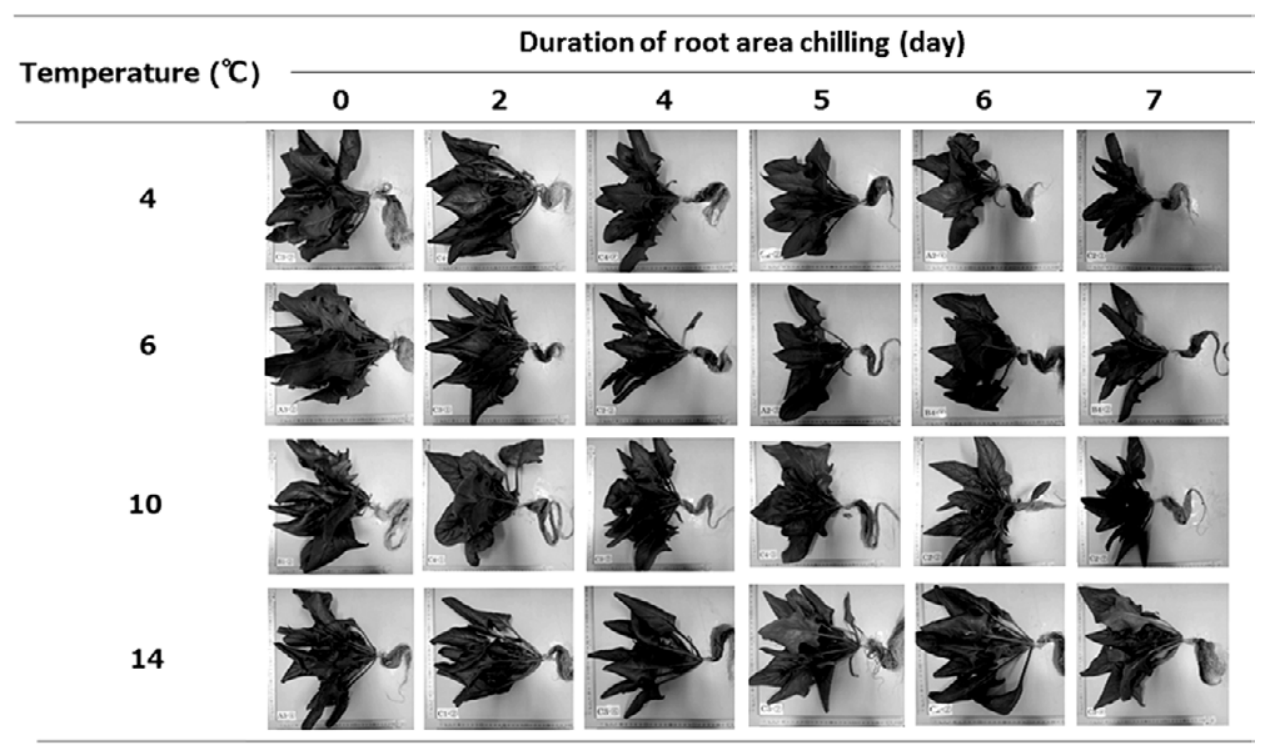

Fig. 2 Physical appearance of spinach plants subjected to different levels of chilling stress to the root area before harvest. Control (four pictures on the left), spinach plants were grown for 0 days at low temperature in the nutrient solution at $18^{\circ} \mathrm{C}$.

Table 1 Effect of different levels of cold stress to the root area on the fresh weight $(\mathrm{g})$ of the aerial part of the plant.

\begin{tabular}{ccccccc}
\hline \multirow{2}{*}{$\begin{array}{c}\text { Temperature } \\
\left({ }^{\circ} \mathrm{C}\right)\end{array}$} & 0 & 2 & 4 & 5 & 6 & 7 \\
\cline { 2 - 6 } & $76.4 \pm 9.70 \mathrm{a}$ & $78.2 \pm 17.6 \mathrm{a}$ & $35.3 \pm 16.1 \mathrm{~b}$ & $26.8 \pm 5.63 \mathrm{~b}$ & $30.0 \pm 10.1 \mathrm{~b}$ & $28.3 \pm 6.35 \mathrm{~b}$ \\
4 & $72.8 \pm 28.1 \mathrm{a}$ & $55.7 \pm 16.5 \mathrm{ab}$ & $50.2 \pm 11.0 \mathrm{ab}$ & $30.7 \pm 4.74 \mathrm{~b}$ & $29.0 \pm 9.07 \mathrm{~b}$ & $25.6 \pm 5.61 \mathrm{~b}$ \\
6 & $79.4 \pm 25.4 \mathrm{a}$ & $60.3 \pm 24.1 \mathrm{ab}$ & $68.6 \pm 19.3 \mathrm{ab}$ & $57.0 \pm 26.5 \mathrm{ab}$ & $33.4 \pm 15.1 \mathrm{~b}$ & $34.8 \pm 14.2 \mathrm{~b}$ \\
10 & $75.6 \pm 29.1 \mathrm{a}$ & $50.4 \pm 13.8 \mathrm{ab}$ & $43.6 \pm 13.7 \mathrm{~b}$ & $46.4 \pm 14.3 \mathrm{ab}$ & $45.1 \pm 12.9 \mathrm{ab}$ & $38.8 \pm 10.5 \mathrm{~b}$ \\
\hline 14 & &
\end{tabular}

Means \pm standard deviations. Different lower case letters in each horizontal row denote significant differences by Ryan's multiple comparison test at $P<0.05(n=5)$. 
A. ITO ET AL.

Table 2 Effect of different levels of cold stress to the root area on the dry matter percentage (\%).

\begin{tabular}{|c|c|c|c|c|c|c|}
\hline \multirow{2}{*}{$\begin{array}{c}\text { Temperature } \\
\left({ }^{\circ} \mathrm{C}\right)\end{array}$} & \multicolumn{6}{|c|}{ Duration of root area chilling (day) } \\
\hline & 0 & 2 & 4 & 5 & 6 & 7 \\
\hline 4 & $5.86 \pm 0.34 \mathrm{~b}$ & $6.04 \pm 0.43 \mathrm{~b}$ & $9.64 \pm 2.93 \mathrm{a}$ & $9.41 \pm 1.20 \mathrm{a}$ & $9.60 \pm 2.08 \mathrm{a}$ & $9.80 \pm 1.35 \mathrm{a}$ \\
\hline 6 & $6.28 \pm 0.30 \mathrm{c}$ & $5.63 \pm 0.20 \mathrm{~d}$ & $6.56 \pm 0.61 \mathrm{bc}$ & $8.04 \pm 1.15 \mathrm{ab}$ & $7.46 \pm 0.96 \mathrm{~b}$ & $9.56 \pm 1.23 \mathrm{a}$ \\
\hline 10 & $5.80 \pm 0.62 \mathrm{~b}$ & $5.91 \pm 0.52 b$ & $5.89 \pm 0.43 \mathrm{~b}$ & $6.10 \pm 1.09 \mathrm{~b}$ & $9.85 \pm 2.55 \mathrm{a}$ & $7.91 \pm 0.81 \mathrm{a}$ \\
\hline 14 & $6.01 \pm 0.35$ n.s. & $5.23 \pm 0.35$ & $5.19 \pm 0.97$ & $5.67 \pm 0.79$ & $6.79 \pm 0.69$ & $7.33 \pm 2.04$ \\
\hline
\end{tabular}

Dry matter percentage is defined as the value obtained by dividing the dry weight by the fresh weight, and is expressed as a percentage. Means \pm standard deviations. Different lower case letters in each horizontal row denote significant differences by Ryan's multiple comparison test at $P<0.05(\mathrm{n}=5)$.

Table 3 Effect of different levels of cold stress to the root area on the leaf area $\left(\mathrm{cm}^{2}\right)$ of the largest leaf.

\begin{tabular}{clccccc}
\hline \multirow{2}{*}{$\begin{array}{c}\text { Temperature } \\
\left({ }^{\circ} \mathrm{C}\right)\end{array}$} & \multicolumn{5}{c}{ Duration of root area chilling (day) } \\
\cline { 2 - 6 } & \multicolumn{1}{c}{0} & \multicolumn{1}{c}{4} & 5 & 6 \\
\hline 4 & $143 \pm 37.0 \mathrm{ab}$ & $144 \pm 20.9 \mathrm{a}$ & $93.9 \pm 17.8 \mathrm{~b}$ & $71.5 \pm 8.88 \mathrm{c}$ & $72.0 \pm 11.1 \mathrm{bc}$ & $79.0 \pm 21.4 \mathrm{bc}$ \\
6 & $102 \pm 21.4 \mathrm{ab}$ & $121 \pm 20.9 \mathrm{a}$ & $124 \pm 24.2 \mathrm{a}$ & $95.6 \pm 9.98 \mathrm{ab}$ & $70.1 \pm 14.5 \mathrm{~b}$ & $70.5 \pm 11.5 \mathrm{~b}$ \\
10 & $134 \pm 32.9 \mathrm{a}$ & $109 \pm 43.3 \mathrm{ab}$ & $108 \pm 20.4 \mathrm{ab}$ & $145 \pm 35.6 \mathrm{a}$ & $94.0 \pm 21.9 \mathrm{ab}$ & $66.0 \pm 15.9 \mathrm{~b}$ \\
14 & $115 \pm 35.0$ n.s. & $112 \pm 34.6$ & $120 \pm 16.8$ & $132 \pm 19.1$ & $80.0 \pm 11.9$ & $119 \pm 32.0$ \\
\hline
\end{tabular}

Means \pm standard deviations. Different lower case letters in each horizontal row denote a significant difference by Ryan's multiple comparison test at $P<0.05(\mathrm{n}=5)$.

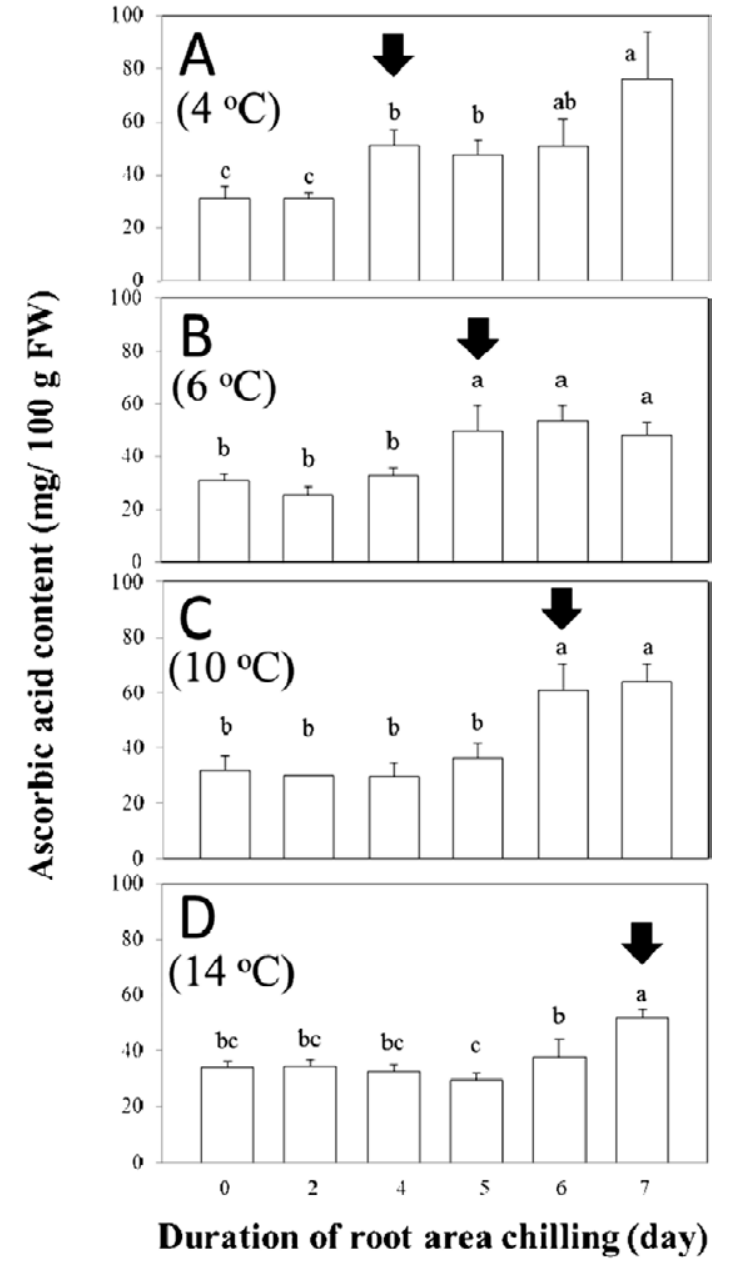

Fig. 3 Effect of the duration of root area chilling at $4^{\circ} \mathrm{C}(\mathrm{A})$, $6^{\circ} \mathrm{C}(\mathrm{B}), 10^{\circ} \mathrm{C}(\mathrm{C})$, and $14^{\circ} \mathrm{C}(\mathrm{D})$ on the ascorbic acid content of spinach. The vertical bars indicate the $\mathrm{SD}(n$ $=5$ ). Means with different letters within each panel are significantly different at the 5\% level by Ryan's multiple comparison test.

increased with increasing solution temperature. In comparison, dry matter percentage showed the opposite trend. Under the same solution temperature conditions, the dry matter percentage increased with increasing chilling duration, except for the when the solution temperature was regulated at $14^{\circ} \mathrm{C}$.

Figure 3 shows the effect of the duration of root area chilling on ascorbic acid content under each solution temperature. Under all solution temperature conditions, the ascorbic acid content increased with increasing chilling duration. The experimental duration that first showed a significant increase in ascorbic acid content compared to the control differed depending on the solution temperature. The chilling duration that first showed a significant change in ascorbic acid content was 4 days at $4^{\circ} \mathrm{C}, 5$ days at $6^{\circ} \mathrm{C}$, 6 days at $10^{\circ} \mathrm{C}$, and 7 days at $14^{\circ} \mathrm{C}$. The chilling duration required to increase ascorbic acid content tended to be shorter with decreasing solution temperature. Because ascorbic acid content might have already risen by 3 days of chilling at $4{ }^{\circ} \mathrm{C}$, an additional experiment was conducted. The ascorbic acid content value after 3 days of root chilling at $4^{\circ} \mathrm{C}$ was $38.2 \pm 3.96(\mathrm{mg} / 100 \mathrm{~g} \mathrm{FW})$, and was not significantly different to the control (no chilling). Therefore, this confirmed that the duration of root area chilling first showed a significant increase after 4 days at $4^{\circ} \mathrm{C}$.

Figure 4 shows the effect of root area chilling duration on nitrate ion concentration for each solution temperature. Under all temperature conditions, nitrate ion concentration declined significantly within 2 days of the onset of chilling. Nitrate ion concentration decreased with increasing chilling duration under the same solution temperature conditions.

Figure 5 shows the effect of root area chilling duration on soluble solid content for each solution temperature. Soluble solid content showed a similar trend to that of ascorbic acid. The chilling duration at which soluble solid content first significantly increased compared to the control differed depending on the solution temperature of the root area chilling. As observed for ascorbic acid content, the chilling duration at which soluble solid content first significantly changed was 4 days at $4^{\circ} \mathrm{C}, 5$ days at $6^{\circ} \mathrm{C}, 6$ days at $10^{\circ} \mathrm{C}$, and 7 days at $14^{\circ} \mathrm{C}$. The chilling duration required for soluble solid content to increase tended to decline with decreasing solution temperature. Because soluble solid 


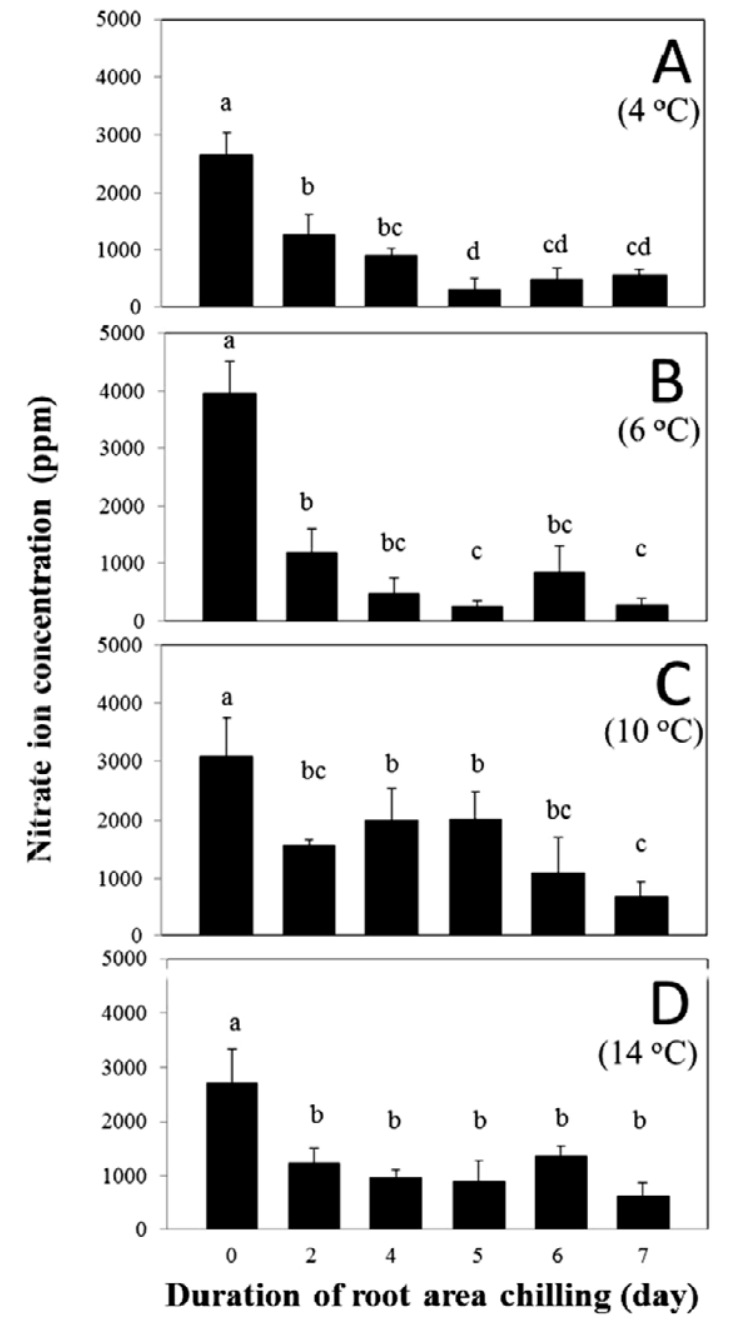

Fig. 4 Effect of the duration of root area chilling at $4^{\circ} \mathrm{C}(\mathrm{A})$, $6^{\circ} \mathrm{C}(\mathrm{B}), 10^{\circ} \mathrm{C}(\mathrm{C})$, and $14^{\circ} \mathrm{C}(\mathrm{D})$ on the nitrate ion concentration of spinach. The vertical bars indicate the SD $(n=5)$. Means with different letters within each panel are significantly different at the 5\% level by Ryan's multiple comparison test.

content might already have increased by 3 days of chilling at $4^{\circ} \mathrm{C}$, an additional experiment was conducted. The Brix value after 3 days of root chilling at $4^{\circ} \mathrm{C}$ was $2.62 \pm 0.20$ $(\%)$, and was not significantly different from the control (no chilling). Therefore, we confirmed that the duration of root area chilling first showed a significant increase after 4 days at $4^{\circ} \mathrm{C}$.

When measuring the amount of ingredients contained in spinach at different levels of cold stress to the root area, ascorbic acid and soluble solid content exhibited a similar pattern (Figs. 3 and 5). For both compounds, a significant increase was observed 4 days after the initiation of root area chilling at $4^{\circ} \mathrm{C}, 5$ days at $6^{\circ} \mathrm{C}, 6$ days at $10^{\circ} \mathrm{C}$, and 7 days at $14^{\circ} \mathrm{C}$ indicated by black arrows in Figs. 3 and 5 . Figure 6 shows the relationship between solution temperature and the chilling duration at which a significant change in ascorbic acid and soluble solid content was first observed in the $x^{-} y$ plane. These data could be approximated to the line $l_{1}$ in Fig. 6, and were expressed as:

$$
\mathrm{y}=0.288 \mathrm{x}+3.05
$$

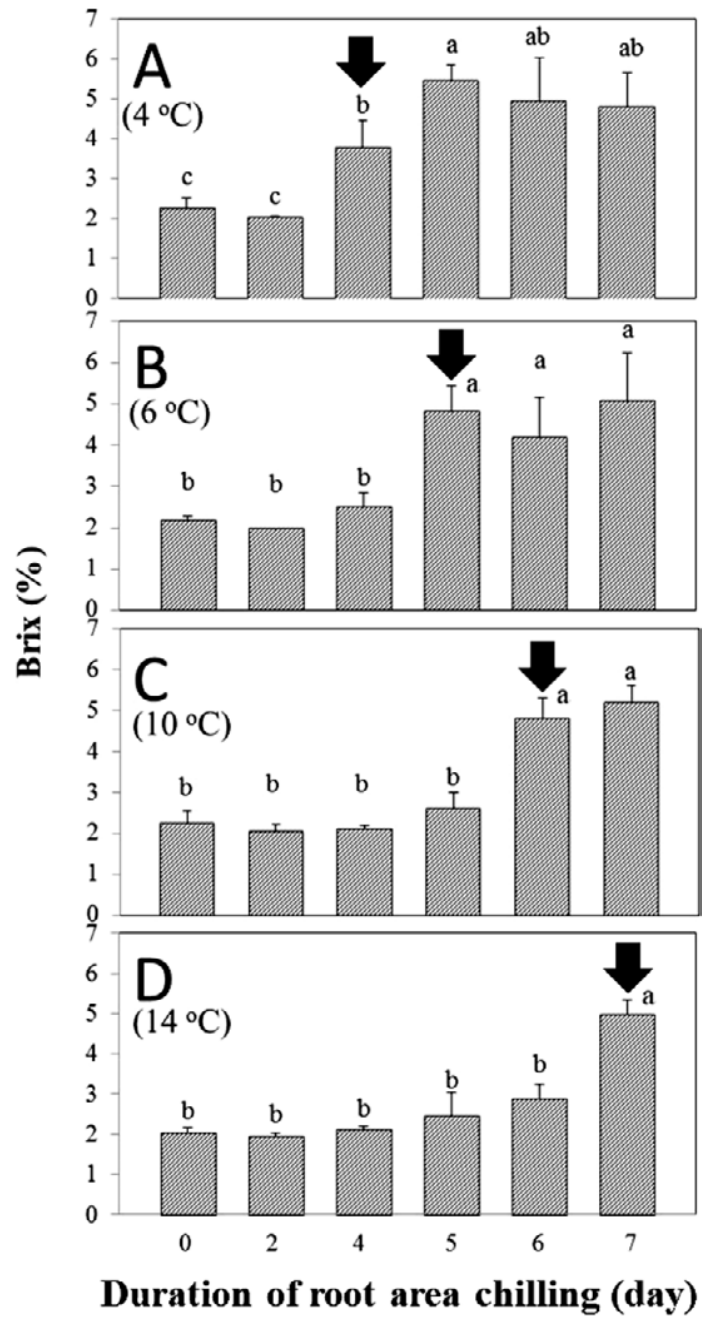

Fig. 5 Effect of the duration of root area chilling at $4^{\circ} \mathrm{C}(\mathrm{A})$, $6^{\circ} \mathrm{C}(\mathrm{B}), 10^{\circ} \mathrm{C}(\mathrm{C})$, and $14^{\circ} \mathrm{C}(\mathrm{D})$ on the Brix of spinach. The vertical bars indicate the SD $(n=5)$. Means with different letters within each panel are significantly different at the 5\% level by Ryan's multiple comparison test.

where $\mathrm{x}$ is the solution temperature and $\mathrm{y}$ is the duration of root area chilling. The triadic relationship between solution temperature, chilling duration, and the amount of each component was determined from the plane parallel to line $l_{2}$, which was expressed as:

$$
y=-3.47 x
$$

line $l_{2}$ is perpendicular to line $l_{1}$, and passes through the origin. line $l_{2}$ was defined as the "x-axis," with the intersection of line $l_{1}$ and line $l_{2}$ being the origin. The distance between line $l_{1}$ and each point was calculated.

The x-coordinate of each dataset was computed according to the following definition:

$$
\begin{array}{ll}
\mathrm{y} \geq 0.288 x+3.05 & \Rightarrow \mathrm{X}=-\mathrm{d} \\
\mathrm{y} \leq 0.288 x+3.05 & \Rightarrow \mathrm{X}=\mathrm{d}
\end{array}
$$

Figures 7 and 8 show the replotting of each dataset on the $\mathrm{x}^{-} \mathrm{y}$ plane, where $\mathrm{X}$ is the value described in the above equations and $\mathrm{Y}$ is the ascorbic acid and soluble solid content, respectively. These two figures show that ascorbic acid and soluble solid content exhibited a sharp increase at 
Duration of root area chilling (day)

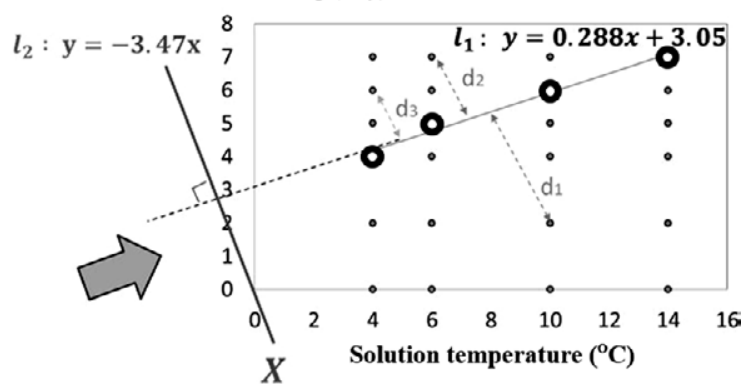

Fig. 6 The triadic relationship of solution temperature, chilling duration, and the amount of each component viewed from the plane panel parallel to line $l_{2}$.

the point $\mathrm{x}=0$. Thus, by adjusting $\mathrm{x}$ and $\mathrm{y}$, so that $\mathrm{y} \geq$ $0.288 x+3.05$, it is possible to produce high value-added spinach in plant factories.

We used the experimental results to develop the relational expression for solution temperature, the duration of root area chilling, and ascorbic acid and soluble solid content. When rhizosphere chilling is implemented by plant factories in Japan and other countries to improve the quality of spinach, the facilities should limit either the number of days spent at low temperatures or the lowest temperature of the solution. In such cases, the relational expression could be used to obtain the minimum solution temperature and the chilling duration required to improve nutritional quality, which would enhance the productivity of the plant factory.

In our experiment, nitrate ion concentration declined significantly within 2 days of starting root area chilling (Fig. 4). In other words, root area chilling for 2 days is sufficient to decrease nitrate ion concentration only. When the plant body is chilled, water absorption by the roots is suppressed because of an increase in the viscosity of the nutrient solution and the reduced fluidity of the root cell membrane due to the reduced activity of aquaporin, which is a protein that transports water across the membrane (Fennell and Marekhart, 1998).

The suppression of water absorption may cause the underground part of the root to respond directly to the change in thermal conditions, without the mediation of the above ground organ. Results from previous studies support the theory that plant roots have temperature sensors and that they regulate water absorption independent of the other parts of the plant. Hydroponically cultivated soybean continues to absorb nitrate ions at the same rate throughout the day, regardless of changes in the environmental conditions, such as light intensity and air temperature. This pattern of nitrate ion absorption was also observed in plants grown under continuous dark conditions or in root-resected aerial parts, and was found to be absent when the roots were maintained at a constant temperature (Ohyama et al., 1989). These results indicate that roots might be able to differentiate between day and night, and that they modulate the absorption rate of nitrate ions as required (Ohyama, 1995). In addition, a previous study reported that barley roots detect thermal changes via temperature sensors (Takagi, 1990).

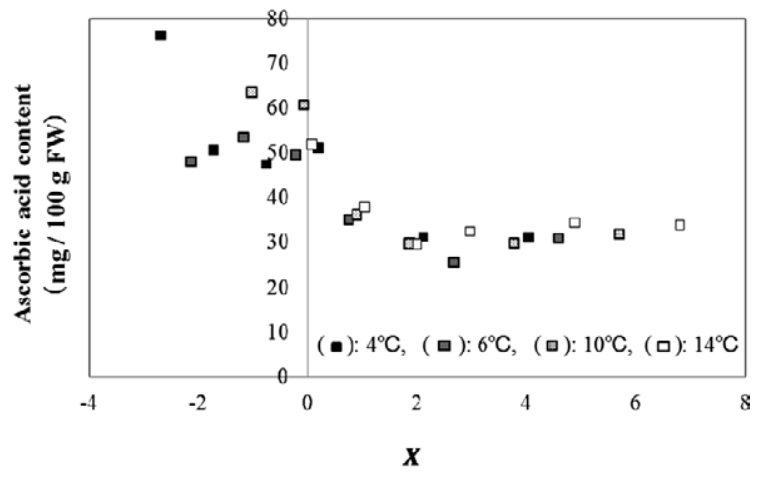

Fig. 7 Relationship between the $\mathrm{x}$-value and the ascorbic acid content. $\mathrm{x}$ is the value determined from the distance between line $l_{1}$ in Fig. 6 and each data point. Each symbol indicates a difference in the solution temperature during chilling treatment.

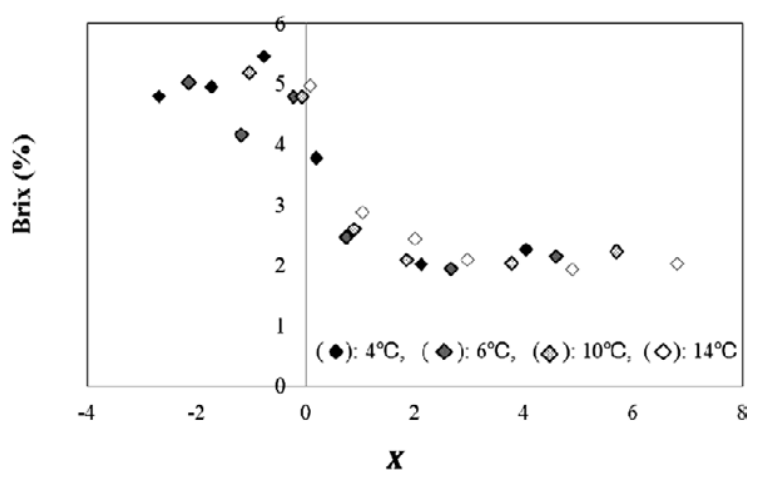

Fig. 8 Relationship between the $x$-value and Brix. $x$ is the value determined from the distance between line $l_{1}$ in Fig.6 and each data point. Each symbol indicates a difference in the solution temperature during chilling treatment.

The temperature detecting-signal transduction mechanism of the plant body remains poorly understood. However, plant roots are likely to detect thermal changes independent of other organs; this information, along with changes in signal reception and photosynthetic products from the aboveground parts, enable them to regulate their response.

Phototropin 1 is a blue light photoreceptor that is located in the top of the plant root, and contributes to root elongation, which induces drought tolerance (Galen et al., 2007). If the sensor detects a change to the environment surrounding the plant root, it would be worthwhile enhancing the nutritional quality of the above-ground part by inducing stress or stimulation to the root area alone. Thus, future studies should not only focus on the vegetative response of plants under plant factory environmental conditions, but should also aim to elucidate the transduction mechanism between the aboveground and underground parts. This information could then be applied to establish novel and efficient cultivation technology based on these mechanisms.

The decrease in water absorption caused by cold stress to the root area leads to a decrease in the amount of nitrate ions that are absorbed from the roots. However, the plant body must produce amino acids and synthesize proteins to 
sustain life. Consequently, nitrate ions that have previously accumulated in the plant body as a source of nitrogen are used (Aoki, 2007). As shown in Fig. 4, the control plants (no chilling) at $6^{\circ} \mathrm{C}$ had the highest nitrate ion concentration. Assuming that all nitrate ions contained in the plant body were used for the production of amino acids and the biosynthesis of proteins during chilling treatment, the fresh weight, dry matter percentage, and leaf area after chilling treatment would be expected to be highest under all other cultivation conditions. However, plants cultivated under all other conditions had higher fresh weight, dry matter percentage, and leaf area compared to those maintained at $6^{\circ} \mathrm{C}$ (Tables 1,2, and 3). This result indicates that other mechanisms contribute to the decrease in nitrate ion concentrations after chilling.

Several studies have reported that plant roots are important for the short- and long-term storage of nitrogen. In particular, woody plants and bulb plants accumulate nitrogen in their roots during winter, and then transfer nitrogen from the root to the developing part in spring (Ohyama, 1985). In our experiment, we did not measure the nitrate ion concentration contained in the root area after the chilling treatment. Therefore, we can only speculate on the changes in nitrate ion concentrations under cold stress. Nevertheless, our results indicate that the minimum amount of nitrate ions required to maintain life is regulated by the aboveground part of the plant, with only excess nitrate ions being stored in the root.

From this study, several questions remain unanswered. The relational expression for solution temperature, the duration of root chilling, and ascorbic acid and soluble solid content developed in this study is only applicable if $\mathrm{x}$ (the solution temperature) is $4^{\circ} \mathrm{C} \leqq \mathrm{x} \leqq 14^{\circ} \mathrm{C}$. When the temperature of the solution is regulated at less than $4^{\circ} \mathrm{C}$, the change in ascorbic acid and soluble solid content remains uncertain. In addition, the relational expression derived in this study might differ depending on the growth stage at which the cold stress is applied. Here, we have limited application of cold stress to the period just before harvest. However, further research will be performed to study the application of cold stress at different growth stages, and its relationship with solution temperature, duration of root chilling, and soluble solid content. Furthermore, this triadic relationship has a histogram-based threshold, with at least 50 experimental conditions being required. Because only 24 experimental conditions were assessed in this study, we could not obtain the threshold value through the histogram. Further studies under various conditions are needed to elucidate the full relationship between root area temperature, duration of low temperature conditions, and the nutritional quality of spinach. The disadvantage of the cultivation technique that currently produces high valueadded spinach with root area chilling is a decrease in the size and fresh weight of spinach plants at harvest. Thus, cold stress to the root area using solutions at lower temperatures for short durations may help improve productivity.

\section{CONCLUSIONS}

In this study, the triadic relationship between temperature of nutrient solution during root area chilling, duration of root chilling treatment, and the amount of nutritional compounds in spinach was investigated. Nitrate ion concentration significantly decreased within 2 days of the onset of chilling under all temperature conditions. Ascorbic acid and soluble solid content showed a similar trend, with a significant change occurring at a specific duration in each solution temperature, and the equation for the chilling duration and solution temperature was proposed. This study suggests an approach for producing high value-added spinach under factory conditions using the developed equation.

\section{REFERENCES}

Aoki, K. 2007. Reduction in nitrate content at lower temperature by kanjime. Agri. Hort. 82: 993-997.

Akita, M., Suzuki, T. 2010. Biological and systems engineered approach for highly efficient and high-value-added production in plant factory system. Mem. Faculty. B. O. S. T. Kinki University 26: $23-37$.

Chadirin, Y., Hidaka, K., Takahashi, T., Sago, Y., Wajima, T., Kitano, M. 2011a. Application of temperature stress to roots of spinach I. Effect of the low temperature stress on quality. Environ. Control Biol. 49: 133-139.

Chadirin, Y., Hidaka, K., Sago, Y., Wajima, T., Kitano, M. 2011b. Application of temperature stress to roots of spinach II. Effect of the high temperature pre-treatment on quality. Environ. Control Biol. 49: 157-164.

Chadirin, Y., Sago, Y., Hidaka, K., Wajima, T., Kitano, M. 2012. Application of temperature stress to root zone of spinach III. Effective method for short term application of low and high temperature stress to roots. Environ. Control Biol. 50: 199207.

Fennell, A., Marekhart, A. H. 1998. Rapid acclimation of root hydraulic conductivity to low temperature. J. Exp. Bot. 49: 879-884.

Fujiwara, T., Kumakura, H., Ohta, S., Yoshida, Y., Kameno, T. 2005. Seasonal variation of L-ascorbic acid and nitrate content of commercially available spinach. Hortic. Res. 4: 347352.

Galen, C., Rabenold, J. J., Liscum, E. 2007. Functional ecology of a blue light photoreceptor: effects of phototropin-1 on root growth enhance drought tolerance in Arabidopsis thaliana. New Phytol. 173: 91-99.

Ito, A., Shimizu, H., Hiroki, R., Nakashima, H., Miyasaka, J., Ohdoi, K. 2013. Effect of different duration of root area chilling on the nutritional quality of spinach. Environ. Control Biol. 51: 187-191.

Kitano, M., Hidaka, K., Zushi, K., Araki, T. 2008. Production of value-added vegetables by applying environmental stresses to root in soil-less culture. J. SHITA 20: 210-218.

Ohyama, T. 1985. Nitrogen accumulation in the roots of tulip plants (Tulipa gesneriana). Soil Sci. Plant Nutr. 31: 581-588.

Ohyama, T., Saito, K., Kato, N. 1989. Diurnal rhythm in nitrate absorption by roots of soybeans. Soil Sci. Plant Nutr. 35: $33^{-}$ 42.

Ohyama, T. 1995. Absorption and metabolism of nitrogen in plant roots. Jpn. Soc. Root Res. 4: 85-91.

Shishido, T. 2008. Sugar content of winter spinach and estimation of sugar. Bull. Iwate Agric. Res. Cent. 61: 185-186. 


\section{A. ITO ET AL.}

Takagi, S. 1990. Nutrient physiology of metallic compound. Hakuyu-sya, Tokyo, p 6-51.

Tamura, A. 2004. Effect of air temperature on the content of sugar and vitamin $\mathrm{C}$ of spinach and komatsuna. Hortic. Res. 3: $187-190$.

Takebe, M., Yoneyama, T. 1995. An analysis of nitrate and ascorbic acid in crop exudates using a simple reflection photometer system. J. Soil Sci. Plant Nutr. 66: 155-158.

Tsukazawa, K. 2002. Study of simplicity measurement methods of deoxidize type vitamin $\mathrm{C}$ and $\mathrm{B}$-carotene content in vegetables. Bull. Saitama Pref. Agric. For. Res. Cent. 2: 43-46. 